\title{
Fatigue Crack Propagation Behavior in Residual Stress Fields of Laminated Inhomogeneous Metals*
}

\author{
Tashiyuki TORII**, Kazuo HONDA** and Tsukasa HOHJOH***
}

\begin{abstract}
Clad plates composed of low-carbon and high-carbon steels were prepared in order to investigate the effects of laminated inhomogeneity and residual stress distribution along the thickness on fatigue crack propagation behavior. The fatigue crack propagation rates of the tempered clad plate without residual stress were between those of both base metals, which showed behavior based on the law of mixture. The fatigue crack propagation rates of the quenched clad plates with residual stress were lower than those of either base metal under the same fatigue conditions. This was because the crack opening displacement, even in unhardened parts with tensile residual stress, was suppressed by the crack front curved due to the residual stress field balanced along the thickness, in which the stress intensity factor due to the residual stress was estimated to be almost zero.
\end{abstract}

Key Words: Fatigue, Crack Propagation, Residual Stress, Stress Intensity Factor, Crack Opening Displacement, Composite Material

\section{Introduction}

It is well known that residual stresses are very important factors controlling fatigue lives of machine parts. The residual stress effect on fatigue crack propagation behavior has often been reported for a fatigue crack propagating only through a field of either tensile or compressive residual stress near the crack tip ${ }^{(1)-(6)}$. However, because residual stresses are often distributed along the thickness in laminated inhomogeneous plates, it is necessary for us to discuss the fatigue crack behavior propagating near the crack tip through the fields of both tensile and compressive residual stresses balancing along the thickness. This crack behavior may not be explained simply in terms of the well-known effect in which the fatigue crack propagation accelerates or decelerates in the tensile or the compressive residual stress field, respectively.

* Received 20th July, 1992. Paper No. 91-0470A.

** Faculty of Engineering, Okayama University, 3-1-1 Tsushima-naka, Okayama 700, Japan

*** Graduate School, Faculty of Engineering, Okayama University, 3-1-1 Tsushima-naka, Okayama 700, Japan
To understand such complicated fatigue crack behavior, its controlling parameters must first be examined experimentally. In fact, the two main parameters of residual stress and laminated inhomogeneity are considered to be important for the fatigue crack propagation of laminated inhomogeneous metals.

In a previous paper ${ }^{(7),(8)}$, the authors used a clad plate composed of low-carbon and high-carbon steels as the experimental model specimen for case-hardened materials, such as carburized and induction hardened materials, in which the elastic behavior of the laminated inhomogeneity may not appear. The tempered clad plate without residual stress enabled us to examine the laminated inhomogeneity effect and the quenched clad plate was used to examine the residual stress effect, using base (constitutive) metals known for their mechanical properties.

In this study, tempered and quenched clad plates were also used in order to discuss separately the laminated inhomogeneity and residual stress effects, as in the previous paper ${ }^{(7),(8)}$. With the use of these specimens, the fatigue crack initiation near a small center hole and the subsequent through-crack propagation due to fatigue were examined. As a main 
result, the residual stress field balancing along the thickness had a curved through-crack front, and this crack front curvature played a role in suppressing the crack opening displacement even in the unhardened part with tensile residual stress, decelerating the fatigue crack propagation of the clad plate.

\section{Experimental Procedures}

\subsection{Specimens}

Table 1 shows the chemical compositions of S10C and $\mathrm{S} 45 \mathrm{C}$ used in the experiment. The clad plates of S45C-S10C-S45C (HLH type) and S10C-S45C-S10C (LHL type) were made as follows : each type of plate was sandwiched and welded along the edges in order to protect the interface against oxidation at high temperature and thereafter hot-rolled at $1173 \mathrm{~K}$ and reduced in thickness by $70 \%$. The specimen was machined to the dimensions with a through center hole of $1.0 \mathrm{~mm}$ diameter, as shown in Fig. 1, where the ratio of $\mathrm{S} 45 \mathrm{C}$ thickness to the plate thickness of 3.2 mm (composite ratio $R_{H}$ ) was 0.5 . After annealing at $1173 \mathrm{~K}$ for one hour in a vacuum, the specimen was fatigued under a stress amplitude of $\sigma_{a}=120 \mathrm{MPa}$ and a stress ratio of $R=-1$, until a crack $0.5 \mathrm{~mm}$ in length was made near the notch in order to be used as a crack starter in the following fatigue crack propagation test.

The precracked clad plate thus produced was cooled in oil from $1173 \mathrm{~K}$ so that compressive residual stresses due to martensitic transformation of the S45C constituent were caused. This is referred to as an "oil -quenched specimen". Some of the quenched clad plates were tempered at $873 \mathrm{~K}$ for one hour in a vacuum in order to eliminate the residual stress. These are referred to as "tempered specimens". The heat-treated clad plates were then electropolished. The S10C and S45C base specimens were machined to the same dimensions and were heat-treated under the same conditions as those of the clad plates.

\section{2 Residual stress measurements}

The residual stress distribution in the thickness of

Table 1 Chemical composition

\begin{tabular}{|c|c|c|c|c|c|}
\hline & $C$ & Si & Mn & P & S \\
\hline S10C & 0.11 & 0.27 & 0.47 & 0.013 & 0.015 \\
\hline S45C & 0.45 & 0.18 & 0.78 & 0.012 & 0.006 \\
\hline
\end{tabular}

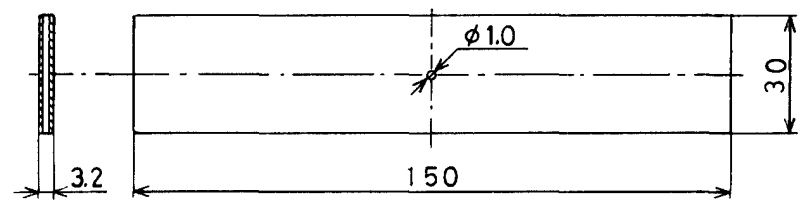

Fig. 1 Dimensions of specimen the clad plate was measured with X-rays after removal of the surface layers from the specimen by electropolishing. The measured stresses were corrected for changes due to the removal of surface layers. The measurement conditions using an $\mathrm{X}$-ray diffraction stress analyzer (DX-10) were as follows: side inclined method for the measurement, $\mathrm{Cr}-\mathrm{K} \alpha$ for a diffraction line, $4 \times 4 \mathrm{~mm}^{2}$ for $\mathrm{X}$-ray radiated area, the half-value breadth method for determining the peak angle in an $\mathrm{X}$-ray profile, the minimum square method for determining the slope of the $\sin ^{2} \psi-2 \theta$ diagram and a stress constant $K$ of $-318.2 \mathrm{MPa} / \mathrm{deg}$.

\section{3 Fatigue tests}

The fatigue tests were performed under tensioncompression sinusoidal wave loads at a speed of $20 \mathrm{~Hz}$ using a servo-hydraulic control fatigue testing machine. Under a stress ratio of $R=-1$, the stress amplitude $\sigma_{a}$ was $100 \mathrm{MPa}$ and $120 \mathrm{MPa}$ for the oilquenched and the tempered specimens, respectively. The fatigue crack length on the specimen surface was measured using a photomicroscope with 100 magnification attached to the testing machine.

\subsection{Measurements of crack front shape and} crack opening displacement distribution

The crack front shape was observed from the mark left on the fracture surface by oxidizing at 523 $\mathrm{K}$ for one hour in air.

Pairs of microvickers impressions marked on either side of the crack at a gage length of about 60 $\mu \mathrm{m}$ were spaced at $0.1 \mathrm{~mm}$ intervals along the crack, except near the crack tip where the intervals were $0.05 \mathrm{~mm}$. The distance for a pair of impressions was measured by an image processing system using a TV camera connected to a photomicroscope ${ }^{(9)}$. The difference between the distance measured under loading and unloading was defined as the crack opening displacement at the position indicated by microvickers impressions along a crack.

\section{Experimental Results}

\section{1 Distributions of residual stress and hardness}

Figure 2 shows the residual stress distribution measured along the thickness of the oil-quenched clad plate; compressive residual stress occurred in the S45C part, while tensile residual stress occurred in the S10C part for both HLH and LHL types. Moreover, these stresses were equally distributed in longitudinal and transverse directions. On the other hand, those residual stresses due to martensitic transformation of the $\mathrm{S} 45 \mathrm{C}$ part were found to be eliminated for the tempered clad plate.

For both the oil-quenched and the tempered clad plates shown in Fig. 3, the hardness changed continually according to the carbon content diffused from the 
$\mathrm{S} 45 \mathrm{C}$ to the S10C region, in both the HLH type hardened in the case and LHL type hardened in the interior. The hardness of both the hardened and unhardened parts was found to be nearly equal to that of S45C and S10C base metals subjected to the same heattreatment as the clad plate; namely, hardness $H_{V}=690$ (S45C) and $H_{V}=210$ (S10C) for the oil-quenched specimens, hardness $H_{V}=270(\mathrm{~S} 45 \mathrm{C})$ and $H_{V}=115$ (S10C) for the tempered specimens.

\section{2 Fatigue crack propagation curves}

Figure 4 shows the fatigue crack propagation curves of the tempered specimen under a stress amplitude of $\sigma_{a}=120 \mathrm{MPa}$ (stress ratio $R=-1$ ) except for a crack length less than $0.5 \mathrm{~mm}$ in the $\mathrm{S} 45 \mathrm{C}$ base metal where the stress amplitude was $\sigma_{a}=140 \mathrm{MPa}(R=$ $-1)$; the clad plate was located between the two base metals. From this, it follows that there is a difference between HLH and LHL types of clad plates only in the early stage of fatigue crack propagation; the fatigue crack initiation on the surface in the LHL type occurs as early as in the S10C base and the fatigue crack propagation rate in the $\mathrm{HLH}$ type is higher than that in the LHL type.

Figure 5 shows the fatigue crack propagation curves of the oil-quenched specimen in which the fatigue crack of the base metals is generated earlier and propagates faster than in the base metals, especially the $\mathrm{S} 45 \mathrm{C}$ base, of the tempered specimen shown in Fig. 4. This figure also shows that there is the same difference between the HLH and LHL types as in the tempered clad plates for the fatigue crack initiation and the early stage propagation, and that the fatigue crack propagation rates of the clad plate are lower than those of the base metals, especially in the LHL type. In addition, there is no significant difference between the LHL clad plate and the S10C base in fatigue crack initiation lives. From this, it can be proven that the tensile residual stress of the clad plate does not affect fatigue crack initiation.

\section{3 Crack front shapes}

The through-crack front shapes in the tempered specimen are shown in Fig. 6 . The early stage of fatigue propagation shown in Fig. 6(a) is such that the fatigue crack tends to generate and propagate easily in the S10C part, in both the HLH and LHL types of clad plates. As a result, it can be assumed that the fatigue crack observed on the surface was easy to generate but difficult to propagate in the LHL type,while, conversely, it was difficult to generate but easy to propagate in the HLH type, as shown in Fig.
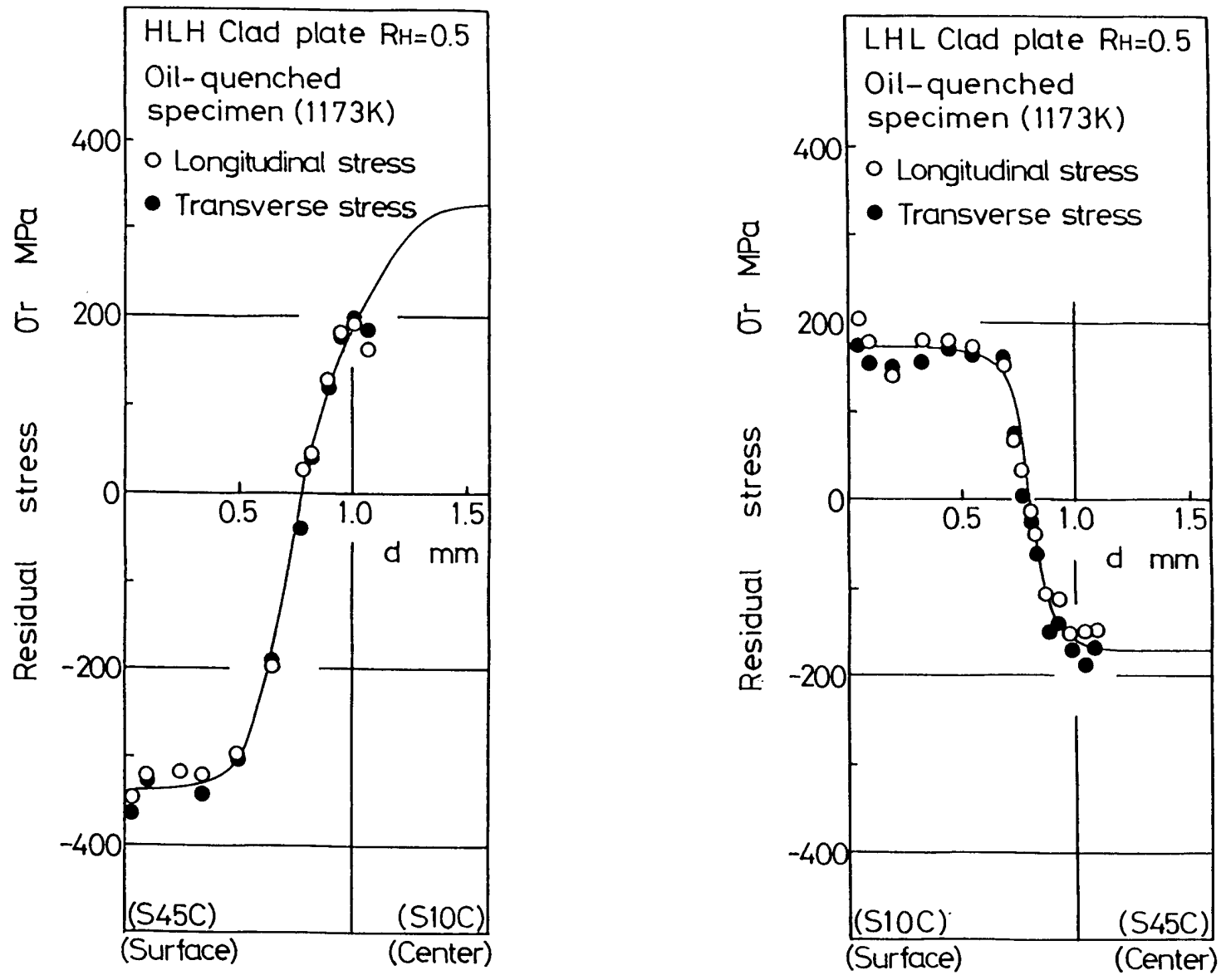

Fig. 2 Residual stress distribution in oil-quenched clad plates 
4. On the other hand, the subsequent propagation stage shown in Fig. 6( b) is such that the crack front becomes essentially a straight line through the thick-

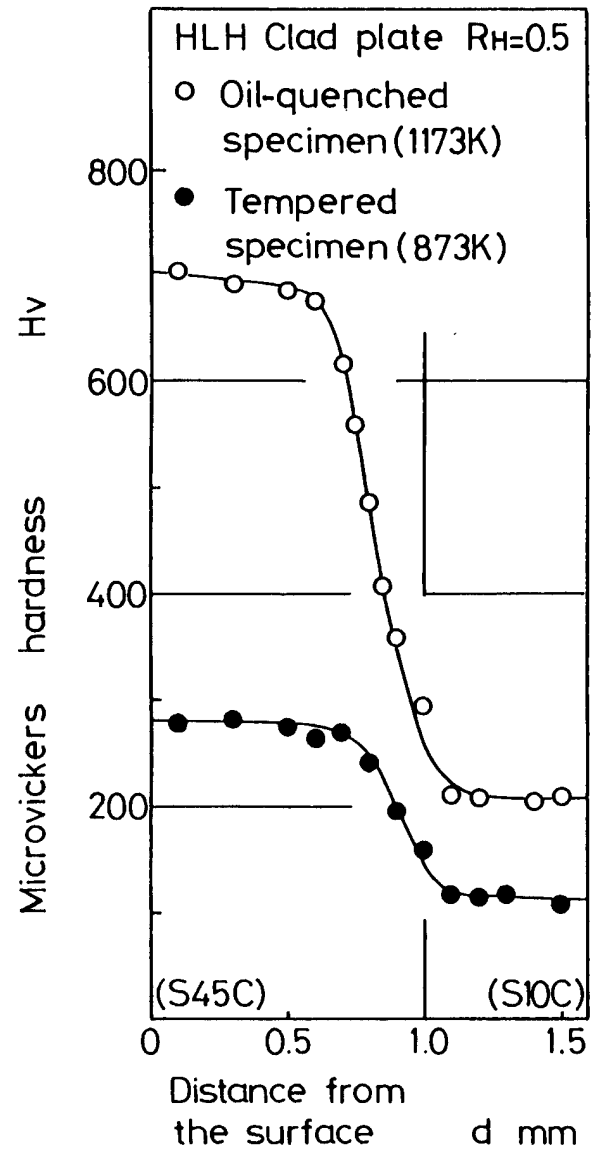

ness of the clad plate and S10C base, indicating that there is no difference between the fatigue crack propagation behavior of the HLH and LHL types of clad

Fig. 3 Hardness distribution in clad plates

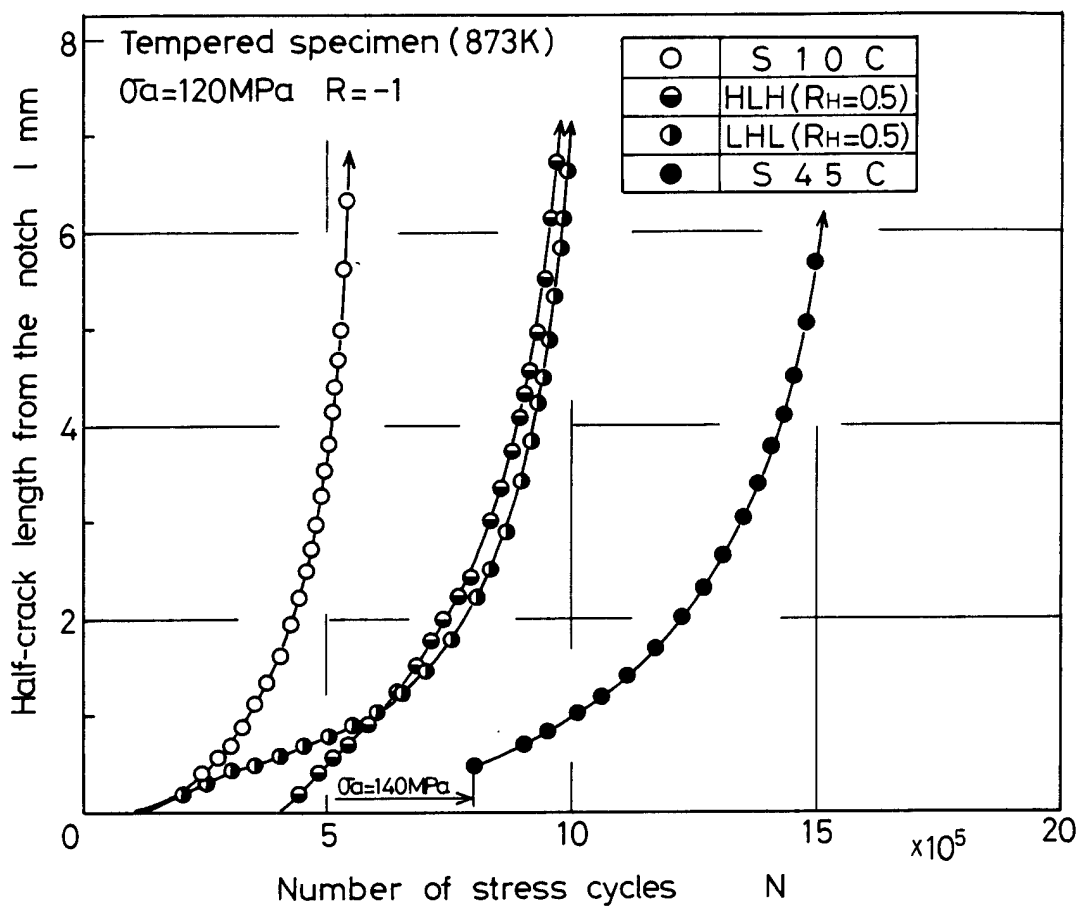

Fig. 4 Fatigue crack propagation curves in tempered specimens 


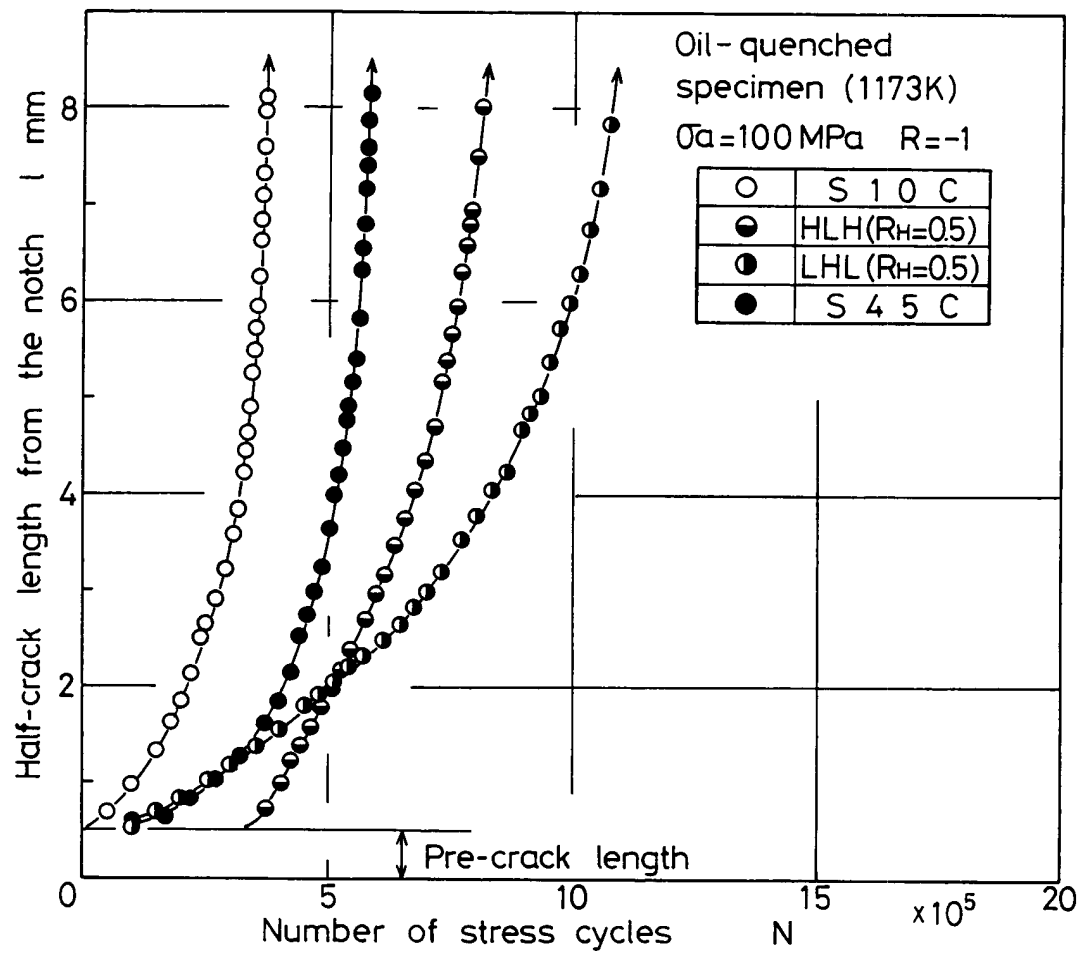

Fig. 5 Fatigue crack propagation curves in oil-quenched specimens

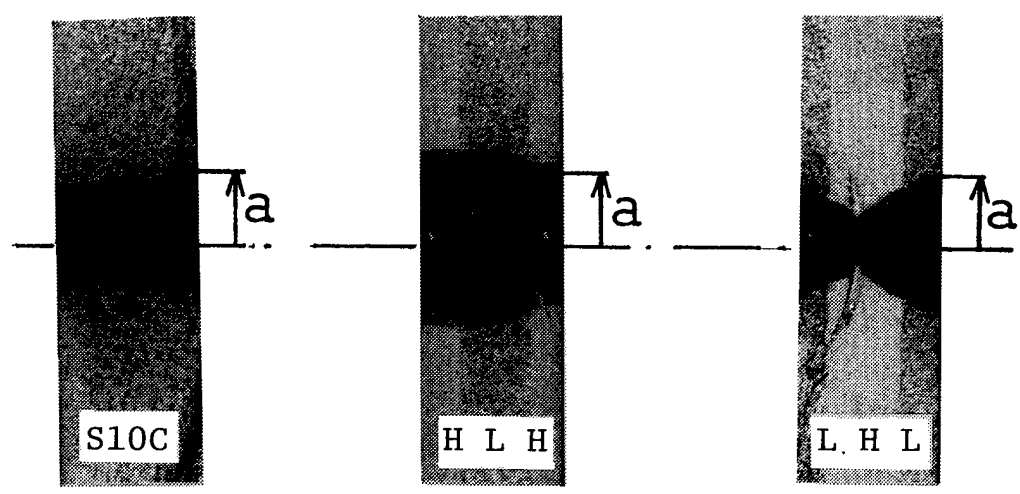

(a) Crack length $a=1.5 \mathrm{~mm}$
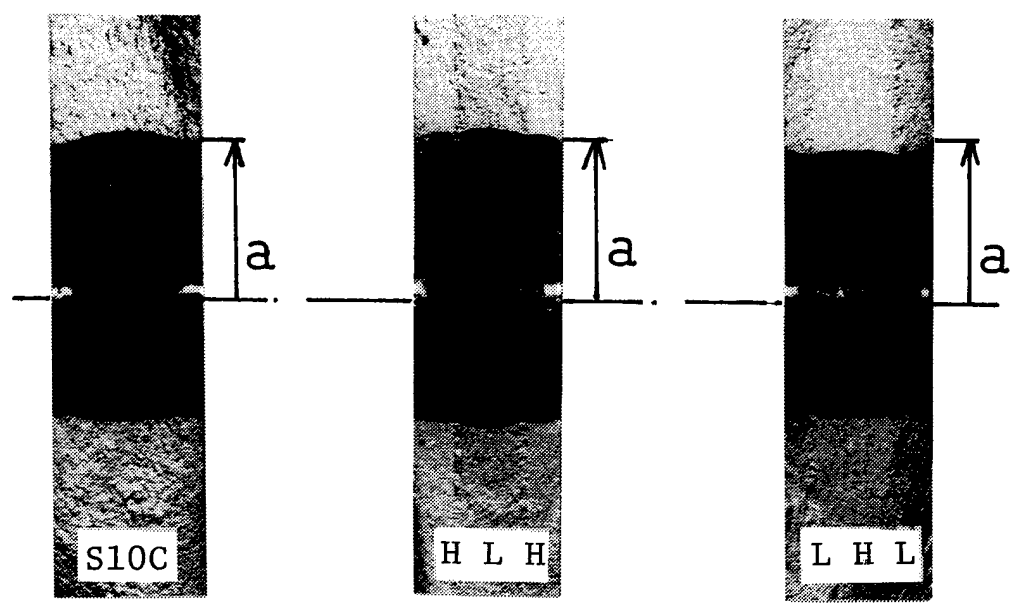

(b) Crack length $a=3.0 \mathrm{~mm}$

Fig. 6 Crack front shapes during fatigue in tempered specimens 


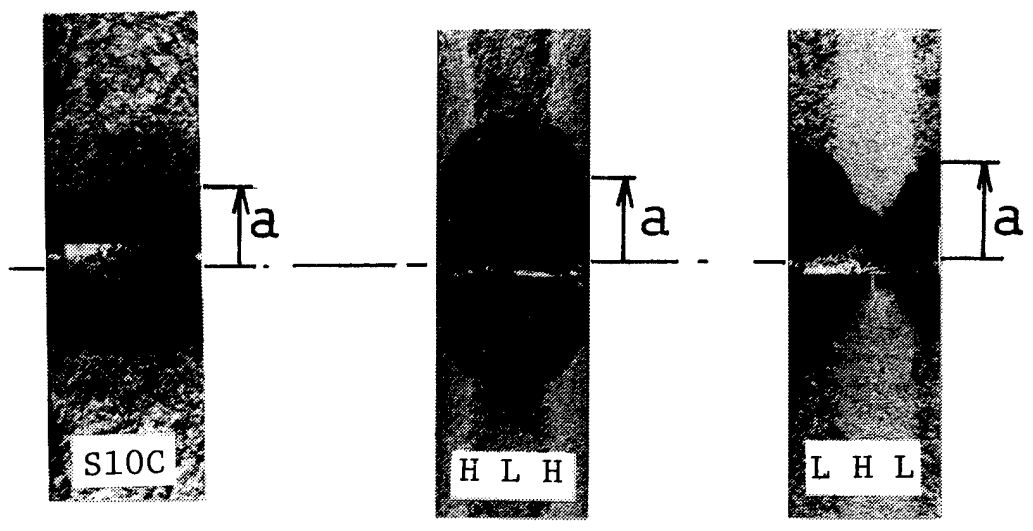

(a) Crack length $a=1.5 \mathrm{~mm}$

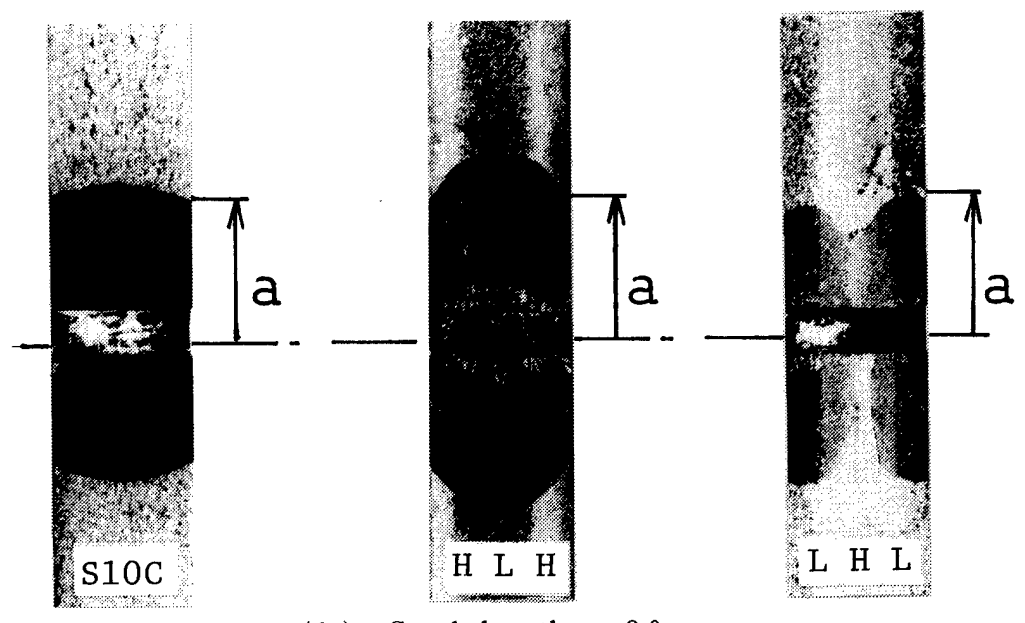

(b) Crack length $a=3.0 \mathrm{~mm}$

Fig. 7 Crack front shapes during fatigue in oil-quenched specimens

plates, as shown in Fig. 4.

The through-crack front shapes in the oil-quenched specimen are shown in Fig. 7. In the relatively small crack of $a=1.5 \mathrm{~mm}$ shown in Fig. 7(a), the crack front curves further as a result of the accelerat. ed propagation in the S10C part of the quenched clad plate than does the crack front in the tempered one, while in the S10C base the crack front nearly straightens. The same results are also seen even in the relatively large crack of $a=3.0 \mathrm{~mm}$ shown in Fig. 7 ( b ). As can be seen from Fig. 7, throughout fatigue crack propagation, the HLH type shows crack behavior along the major axis of an embedded elliptical crack, and the LHL type shows crack behavior of twopart through cracks near the middle of the thickness. Such crack front shape changes are surely attributed to the residual stress field with tension and compression in the S10C and S45C parts, respectively, in the clad plate.In all of the observed crack front shapes, it can be seen in Fig. 8 that the difference between the surface and the inner crack lengths decreases with crack propagation in both the HLH and LHL types of clad plates. On the other hand, the S45C and S10C bases showed that the crack front nearly straightened

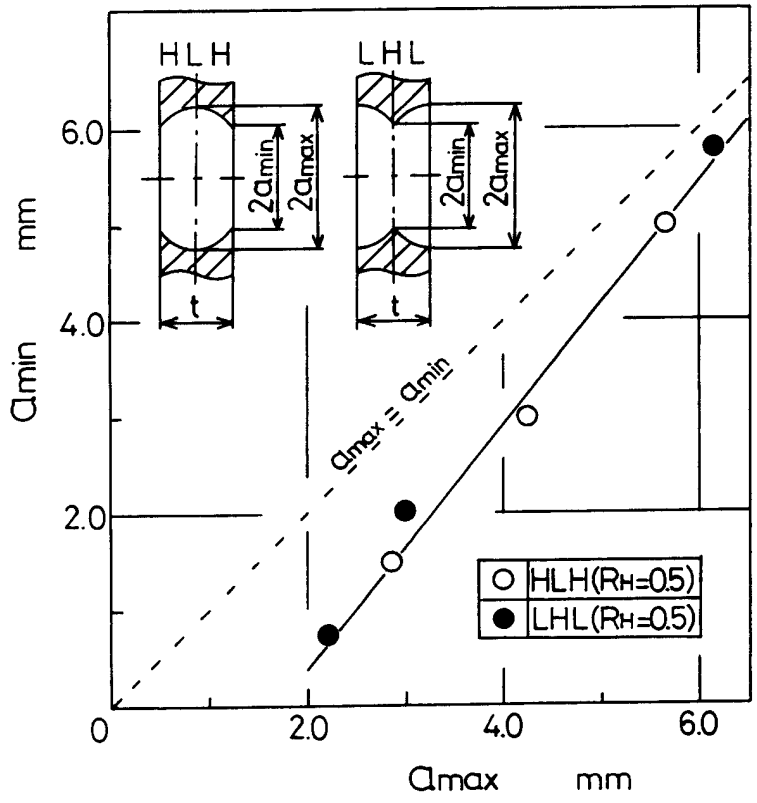

Fig. 8 The difference between fatigue crack lengths on the surface and in the interior of oil-quenched clad plates

through the thickness, although the $\mathrm{S} 45 \mathrm{C}$ was omitted in Figs. 6 and 7. 
Finally, the residual stresses measured after the fatigue fracture in the clad plate were almost the same as the initial ones shown in Fig. 2. This means that the initial residual stress should be considered for the fatigue crack propagation without residual stress relaxation during fatigue.

\subsection{Crack opening behavior and deformation near the crack tip}

In the oil-quenched clad plates and the base metals subjected to various tensile stresses, $\sigma$, the measured displacements for a small distance $(60 \mu \mathrm{m})$ containing a crack are shown in Figs. 9 and 10, respectively. The crack opening behavior will be discussed for the unhardened part with tensile residual stress and for the hardened part with compressive residual stress, using the LHL and the HLH types of clad plates, respectively. In Figs. 9 and 10, it can be seen that the crack tip tends to close in the hardened part and open in the unhardened part, at a relatively small stress level, while the crack tip opening is almost the same in both parts at the maximum stress $(\sigma=100$ $\mathrm{MPa}$ ), and that the deformation near the crack tip under compressive loading occurs only in the unhardened part (LHL). When examined in detail, the crack tip opening stress is a little over $20 \mathrm{MPa}(<50$ $\mathrm{MPa}$ ) in the hardened part (HLH) and about -20 $\mathrm{MPa}$ in the unhardened part (LHL). From this, it is possible that the crack tip will open progressively from the unhardened to the hardened regions of the clad plate in a range of applied stress $\sigma= \pm 20 \mathrm{MPa}$. In this way, although the crack opening stress is difficult to determine as a constant value, the average stress is considered to be zero as compared with the magnitude of the residual stress in the clad plate. On the other hand, there are indications that the tensile and the compressive residual stress fields give positive and negative values, respectively, for the crack opening stress and the stress intensity factors, $K_{r}$, in other reports $^{(1),(3)-(6)}$.

These figures also indicate that the cyclic deformation range near the crack tip under applied stress, $\sigma= \pm 100 \mathrm{MPa}$, is smaller in the unhardened part (LHL) than in the S10C base. Since the unhardened part controls the fatigue crack propagation of the clad plate, it can be understood that the fatigue crack propagation life is larger in the clad plate than in the S10C base, as mentioned in Fig. 5. In addition, the crack tip opening suppressed by the compressive residual stress in the hardened part $(\mathrm{HLH})$ increases abruptly at maximum loading, unlike that in the S45C base. This means that the hardened part of the clad plate may not be fractured by itself but will probably be fractured through the thickness at maximum loading with the aid of the fatigue crack propagating in the unhardened part. It should be noted that the hardened part does not control the fatigue fracture of the clad plate although it has a larger crack opening displacement than that of the $\mathrm{S} 45 \mathrm{C}$ base at maximum

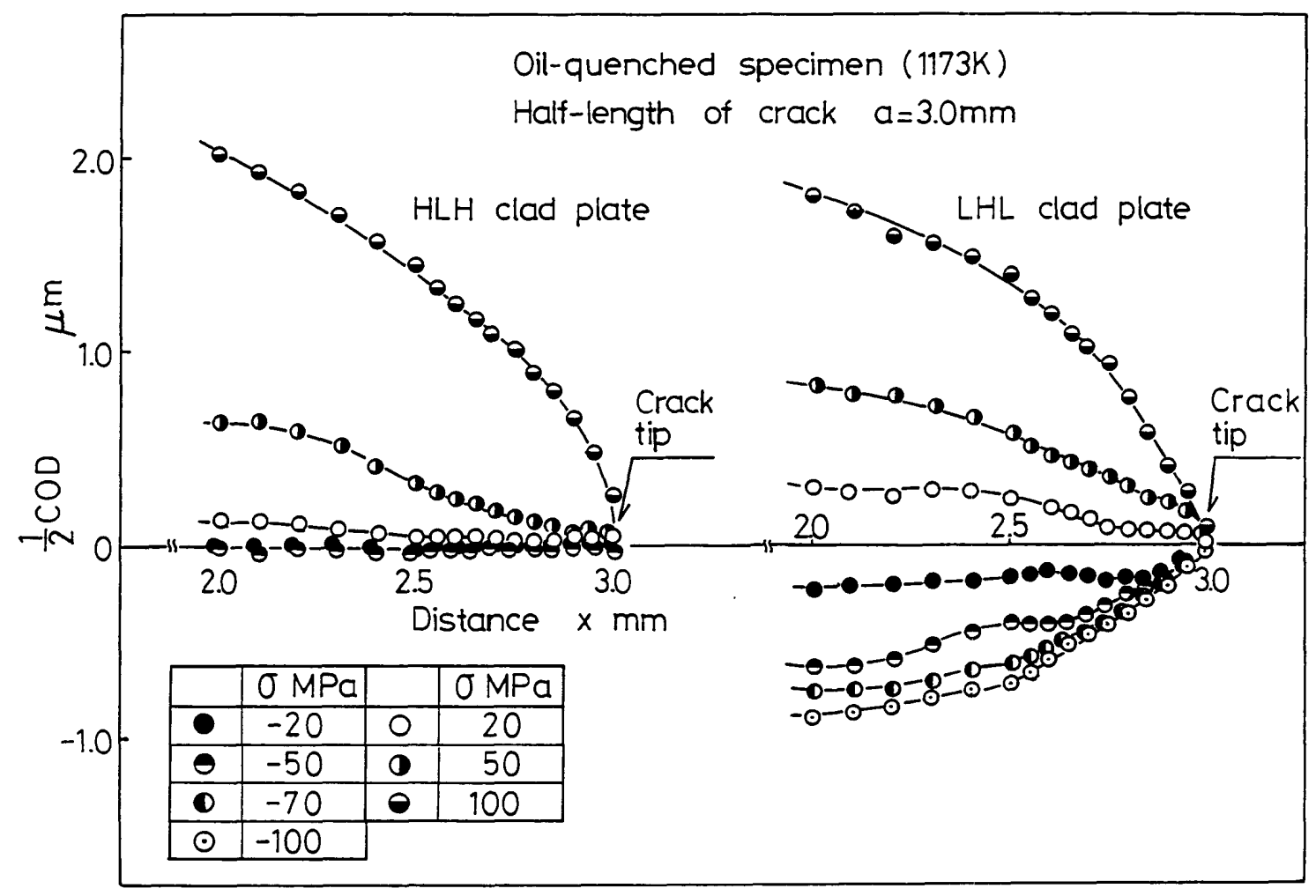

Fig. 9 Deformation behavior near the crack tip in oil-quenched clad plates 
loading. This is also estimated by the authors' previous report as follows : the plastic residual layer in the wake of the propagating crack was liable to accelerate the fatigue crack propagation because it caused shearing deformation near the crack tip at compressive loading(6). A slight compressive deformation is seen in the $\mathrm{S} 45 \mathrm{C}$ base, but it is never seen in the hardened part (HLH) of the clad plate.

\section{Discussion}

4. 1 Stress intensity factors evaluated from crack opening displacement distributions

Fatigue crack propagation rates are closely related to the cyclic deformation near the crack tip which includes both tensile and compressive deformations, depending on the residual plastic layer in the wake of the propagating crack. Because the residual plastic layer is caused by a tensile plastic deformation near the crack tip at maximum loading, the effective stress intensity factor at maximum loading will be the main parameter controlling fatigue crack propagation rates.

Hence, the crack opening displacements (COD) near the crack tip for the clad plates and the S10C base which are closely related to the effective stress intensity factor, are rewritten in Fig. 11 from Figs.9 and 10. In Fig. 11, the measured COD shows that the clad plate with the curved crack front is $(0.6 \sim 0.7)$ times as small as the S10C base in both HLH and LHL types. As reported in the previous paper ${ }^{(10)}$, the stress intensity factor at the major axis of the internal elliptical crack can be evaluated two-dimensionally from the COD distribution on the plane which contains the major axis. Also in this study, using the wellknown equation ( 1 ) for a two-dimensional mode I $\operatorname{crack}^{(11)}$, the stress intensity factors are evaluated even for the curved crack front as follows :

$$
V=\frac{K_{1}}{2 G} \sqrt{\frac{r}{2 \pi}} \sin \frac{\theta}{2}\left(x+1-2 \cos ^{2} \frac{\theta}{2}\right) .
$$

In Eq. ( 1 ) where $\theta=\pi$, shear modulus $G=79.2 \mathrm{GPa}$, $x=2.08$ using Poisson's ratio $\nu=0.3$ under plane stress conditions, the stress intensity factors were calculated from the $\operatorname{COD}(=2 \mathrm{~V})$ measured at various distances from the crack tip, $r(=3.0-x) \mathrm{mm}$ less than $0.5 \mathrm{~mm}$, as shown in Table 2. This table indicates that the stress intensity factors of the clad plate are $0.71 \mathrm{~K}$ and $0.60 \mathrm{~K}$ in the $\mathrm{HLH}$ and LHL types, respectively, using $K$ for the average stress intensity factor of the S10C base.

\section{2 Fatigue crack propagation rates}

In Fig. 12, the fatigue crack propagation rates obtained from the propagation curves of the tempered specimen in Fig. 4 are plotted against the maximum stress intensity factors, $K_{\max }(=\Delta K / 2)$, calculated as a two-dimensional crack with the crack length on the surface. In this figure, in the region of a relatively large crack length (or large $K_{\max }$ ) with a nearly straight crack front, as indicated in Fig. 6(b), the clad

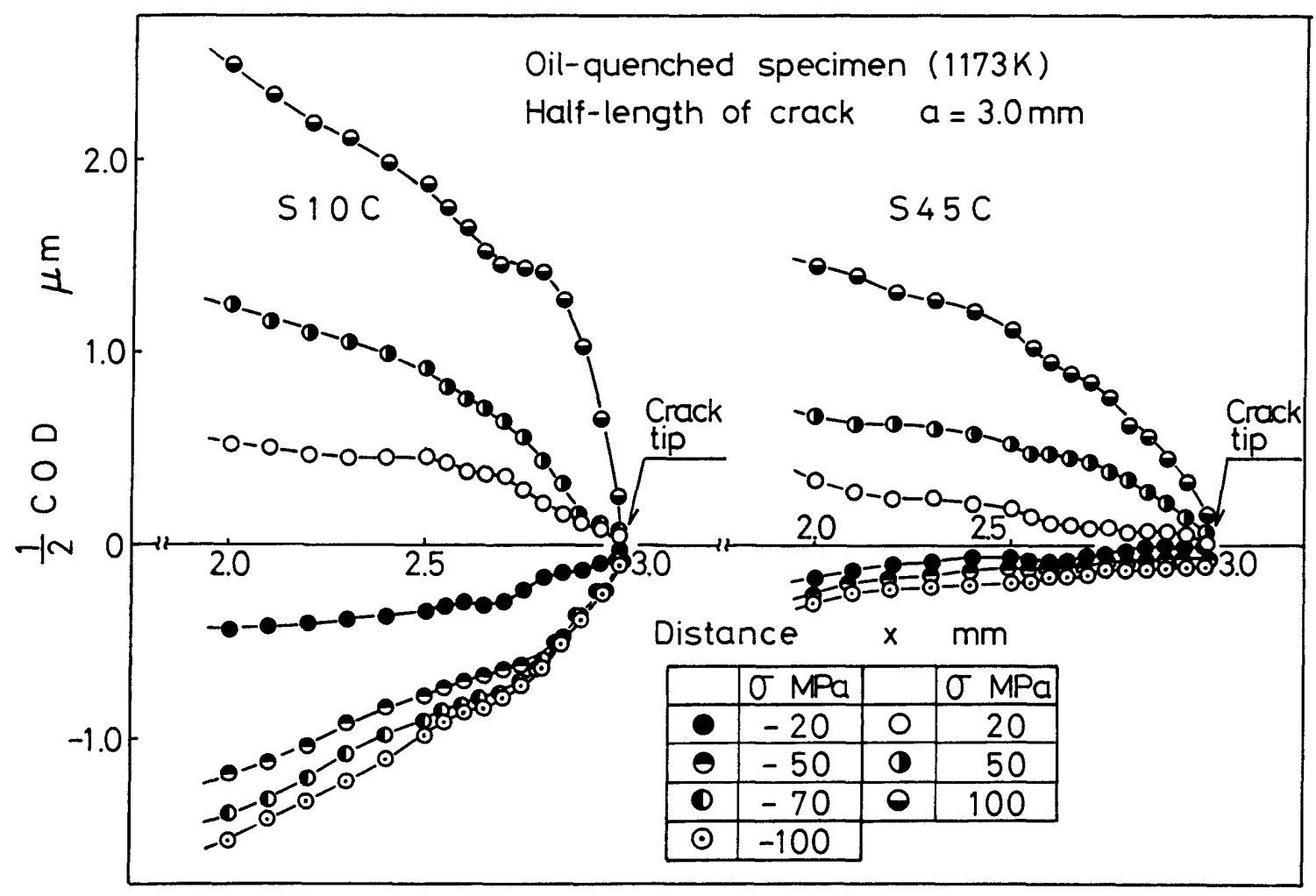

Fig. 10 Deformation behavior near the crack tip in oil-quenched base metals 
plate lies between the two base metals in both the HLH and LHL types, based on the law of mixture for the fatigue crack propagation rate.

In Fig. 13, the fatigue crack propagation rates obtained from the propagation curves of the oil-quenched specimen in Fig. 5 are plotted against the $K_{\max }$ calculated in the same way as in Fig. 12, using circles. In this figure, the circle $\ominus$ used for the HLH type changes to the symbol $\square$ when the $K_{\max }$ is calculated from the maximum crack length $a_{\max }$ of Fig. 8. In this case the $a_{\max }$ is the crack length in the inner unhardened part controlling the fatigue crack propagation of the clad plate. For the LHL type, the crack length on the surface used for the calculation of $K_{\max }$ is also

Table 2 Evaluation of stress intensity factors in oilquenched specimens

\begin{tabular}{|c|c|c|c|}
\hline \multirow[b]{2}{*}{$\mu \mathrm{m}$} & \multicolumn{3}{|c|}{$\mathrm{MPa} \sqrt{\mathrm{m}}$} \\
\hline & $\mathrm{S} 10 \mathrm{C}$ & $\mathrm{HL} \mathrm{H}$ & $\mathrm{L} \mathrm{H} \mathrm{L}$ \\
\hline 50 & 11.91 & 8.87 & 4.93 \\
\hline 100 & 13.40 & 8.62 & 5.33 \\
\hline 150 & 13.55 & 8.35 & 6.17 \\
\hline 200 & 13.05 & 8.17 & 6.94 \\
\hline 250 & 11.84 & 8.21 & 7.71 \\
\hline 300 & 10.94 & 8.18 & 7.66 \\
\hline 350 & 10.56 & 8.10 & 7.65 \\
\hline 400 & 10.63 & 8.07 & 7.68 \\
\hline 450 & 10.65 & 8.08 & 7.85 \\
\hline 500 & 10.89 & 8.32 & 8.17 \\
\hline M & $\begin{array}{c}11.74 \\
(\mathrm{~K}) \\
\end{array}$ & $\begin{array}{c}8.29 \\
(0.71 \mathrm{~K})\end{array}$ & $\begin{array}{c}7.01 \\
(0.60 \mathrm{~K})\end{array}$ \\
\hline
\end{tabular}

the maximum crack length, $a_{\max }$. As a result, using the $K_{\max }$ calculated from the $a_{\max }$, the fatigue crack propagation rate of the clad plate can be approximated by a straight line ( $K$ expression) below those of both base metals, irrespective of the HLH and LHL types. This means that the fatigue crack propagation decelerates in the unhardened part of the clad plate as compared with the S10C base under the same values of maximum crack length and stress amplitude, for which the stress intensity factor $K$ used in the clad plate is overestimated. When one uses the effective stress intensity factor $(0.6 \sim 0.7) \mathrm{K}$ estimated from the crack opening displacement, as shown in Table 2, the clad plates and the base metals are almost the same for the fatigue crack propagation rate, as drawn by the oblique line in Fig. 13.

In many papers, the residual stress effect on fatigue crack propagation behavior has often been discussed as mean stress effects, based on the superposition of the stress intensity factors due to the residual stress $K_{r}$ on those due to the applied stress ${ }^{(1),(3),(4),(6)}$. It should be noted, however, that the stress intensity factor range $\Delta K$ itself can be changed in accordance with the crack front curved due to the residual stress field balanced along the thickness of the clad plate, whereas the value of $K_{r}$ is nearly equal to zero in this residual stress field.

\section{Conclusions}

The tempered and oil-quenched clad plates, composed of low-carbon and high-carbon steels, were

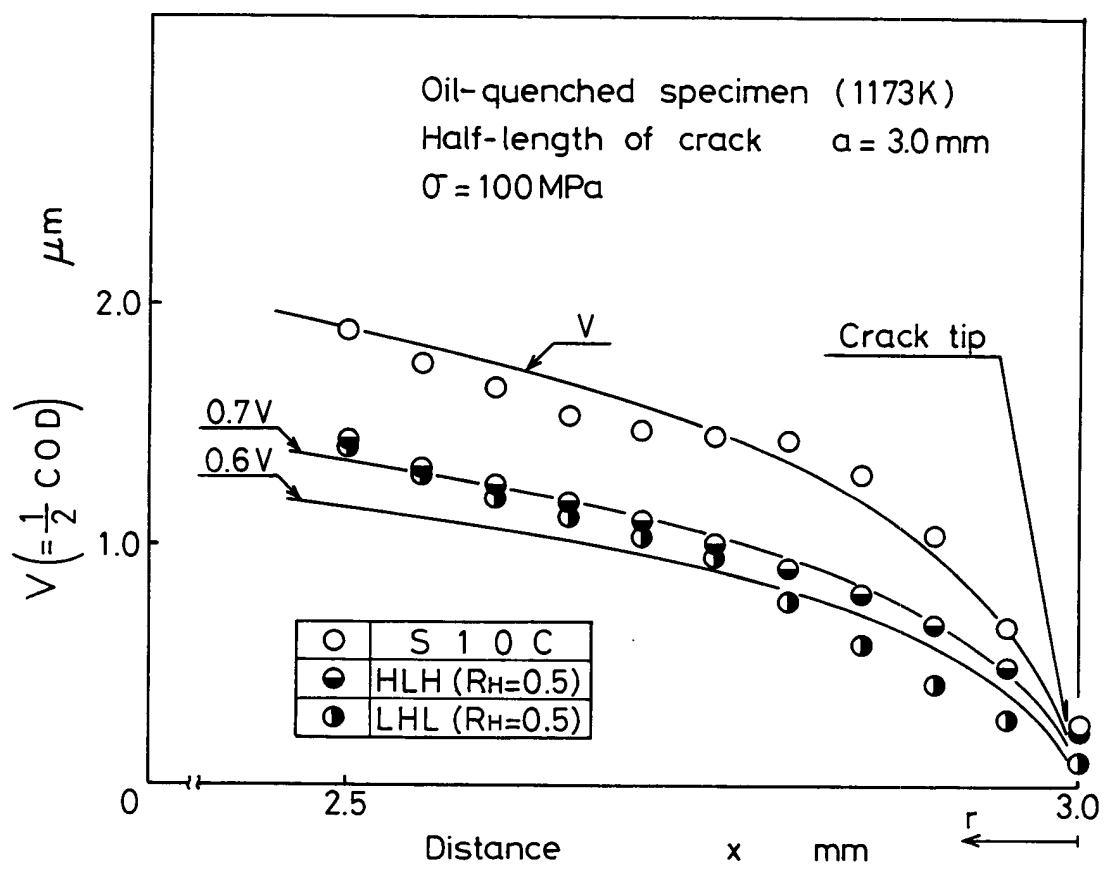

Fig. 11 The difference in crack opening displacement distribution between oil-quenched clad plates and S $10 \mathrm{C}$ base metal 
prepared for laminated inhomogeneity without residual stress and with residual stress, respectively. From a comparison of both heat-treated clad plates, the laminated inhomogeneity and the residual stress effects on the fatigue through-crack propagation behavior were discussed in relation to the crack front shape and the crack opening displacement along a crack. The main results obtained are as follows.

(1) For the tempered clad plate, the fatigue crack in an early stage showed a curved crack front as a result of promoting the propagation in the unhardened part, while the relatively long crack showed a nearly straight crack front as well as in the base metals. Except in the early stage of crack propagation, there is no significant difference in fatigue crack propagation curves between HLH and LHL types, in which the clad plate lies between the two base metals based on the law of mixture for the fatigue crack propagation rates plotted against the maximum stress intensity factor, $K_{\max }$.

(2) For the oil-quenched clad plate, the fatigue crack front was considerably curved toward the thickness for the duration of the fatigue crack propagation. This is because the fatigue crack propagation accelerated in the unhardened part with tensile residual stresses and decelerated in the hardened part with compressive ones. As a result of the observation of the crack opening behavior near the crack tip under various loadings, the stress intensity factor due to this residual stress field balancing along the thickness, $K_{r}$, was considered to be nearly zero. In addition, the crack opening displacements measured near the crack

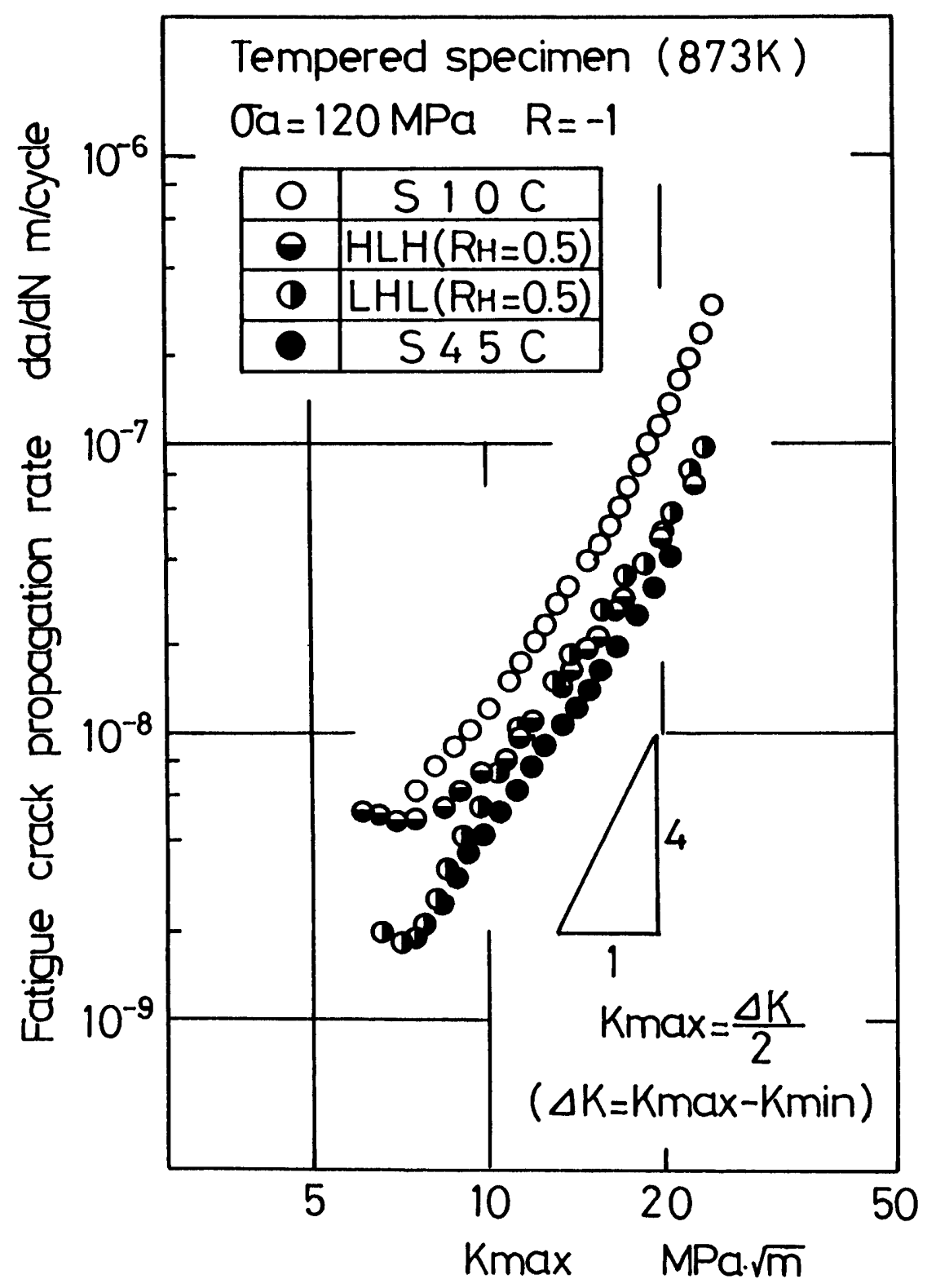

Fig. 12 Fatigue crack propagation rates in tempered specimens 


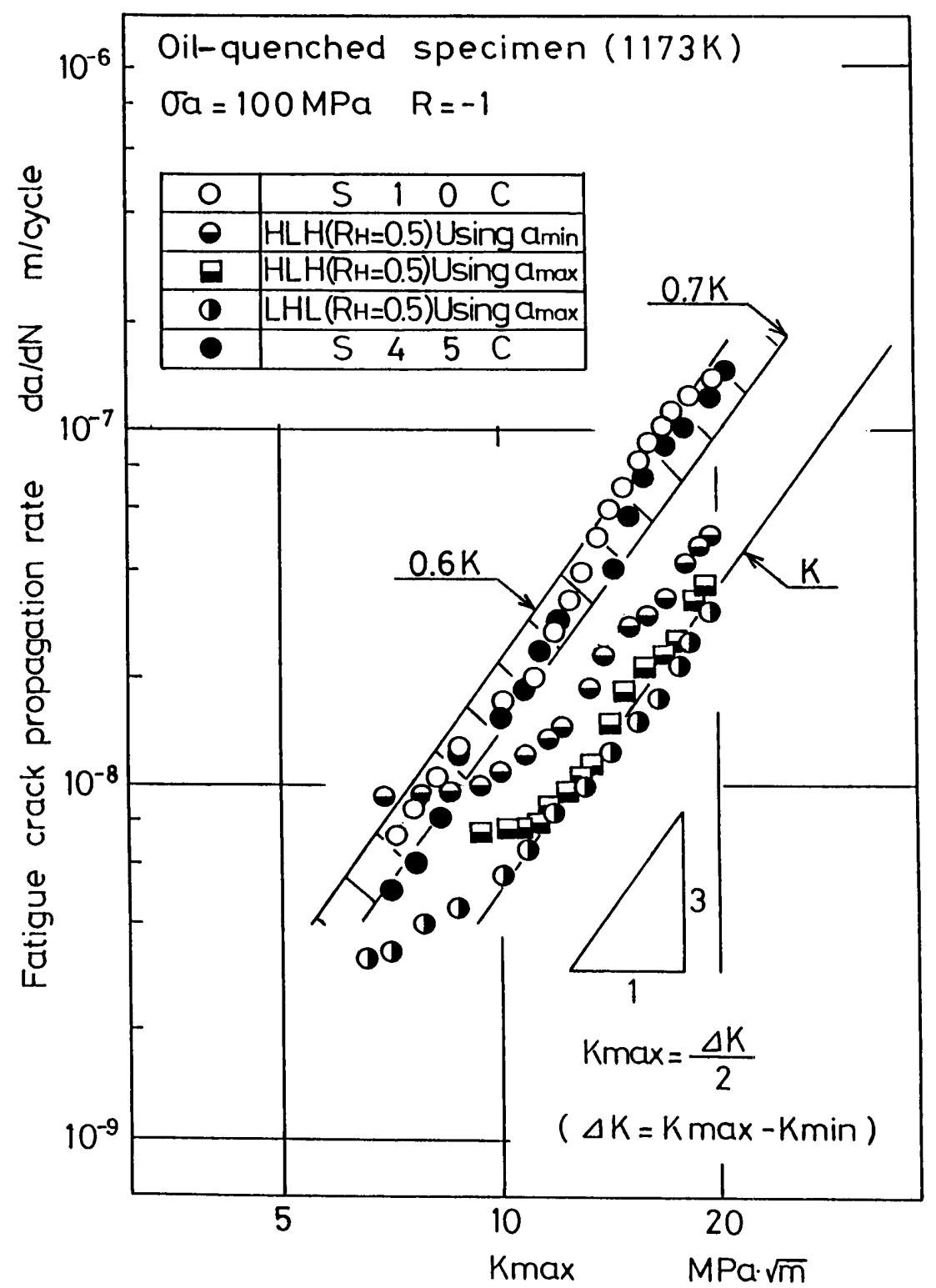

Fig. 13 Fatigue crack propagation rates in oil-quenched specimens

tip of the quenched clad plate, at the maximum loading in fatigue, were $(0.6 \sim 0.7)$ times as small as the values of the S10C base, in both HLH and LHL types.

(3) The fatigue crack propagation rate of the oil-quenched clad plate was lower than that of the S10C base metal, under the same value of the maximum stress intensity factor calculated for the crack length of the unhardened part (S10C) controlling the fatigue crack propagation. This difference could be explained quantitatively by the fact that the clad plate was $(0.6 \sim 0.7)$ times as small as the $\mathrm{S} 10 \mathrm{C}$ base for the effective stress intensity factor evaluated from the crack opening displacement measured near the crack tip.

\section{Acknowledgment}

The authors are grateful to Mr. Masaru Tokuda, for his technical assistance, and also wish to thank Mr. Junichi Sugimoto and Mr. Satoru Ogawara for their help in the experiment.

\section{References}

(1) Ohji, K., Kubo, S., Tsuji, M., Ogawa, H. and Sakurada, K., Methods of Predicting Fatigue Crack Growth Lives in Residual Stress Fields, Trans. Jpn. Soc. Mech. Eng., (in Japanese), Vol. 53, No. 492, A (1987), p. 1516.

(2) Ohta, A., Sasaki, E., Kosuge, M. and Nishijima, S., Fatigue Crack Growth and Threshold Stress Intensity Factor for Welded Joints, JSMS, MRS 1 (1985), p. 157.

(3) Kobayashi, H. and Todoroki, A., Effect of WeldInduced Residual Stress on Fatigue Crack Growth in Compact Specimen, J. Soc. Mat. Sci., (in Japanese), Vol. 35, No. 391(1986), p. 401. 
(4) Kitsunai, Y. and Yoshihisa, E., Fatigue Crack Growth Behavior in Welded Joints of High Strength Steel under Low Temperatures, Trans. Jpn. Soc. Mech. Eng., (in Japanese), Vol. 53, No. 492, A (1987), p. 1525.

(5) Mukai, Y. and Nishimura, A., Opening and Closure Analysis for Fatigue Crack Propagation from Compressive Residual Stress Field, Trans. Jpn. Weld. Soc., Vol. 5, No. 2(1987), p. 272.

(6) Torii, T., Honda, K. and Sugiyama, M., Surface Fatigue Crack Propagation Behavior in a Residual Stress Field (Fatigue Crack Growth Law and Evaluation of Fatigue Crack Propagation Rate), JSME Int. J., Ser. I, Vol. 32, No. 3(1989), p. 450.

( 7 ) Honda, K., Torii, T. and Kumazawa, K., Fatigue Crack Propagation Behavior from the Standpoint of Distinguishing between Laminated Inhomogeneity and Initial Residual Stress, Trans. Jpn. Soc. Mech. Eng., (in Japanese), Vol. 47, No.
416, A (1981), p. 376.

(8) Torii, T. and Honda, K., The Relation Between Bending Fatigue Strength of Laminated Inhomogeneous Plates and Fatigue Crack Growth Law, Trans. Jpn. Soc. Mech. Eng., (in Japanese), Vol.51, No. 464, A (1985), p. 1153.

(9) Torii, T. and Honda, K., Fatigue Crack Growth Testing of Films Using Pre-Cracked Base Plates, Advances in Electronic Packaging, ASME, Vol. 2(1992), p. 707.

(10) Torii, T., Honda, K. and Hikage, J., Evaluation of Stress Intensity Factors of Three-Dimensional Cracks Based on Crack Opening Displacement Distribution, Trans. Jpn. Soc. Mech. Eng., (in Japanese), Vol. 57, No. 536, A(1991), p. 746.

(11) For example, Okamura, H., Introduction to Linear Fracture Mechanics (in Japanese), (1976), p. 21, Baifukan. 